\title{
Preface: Teaching benefit-cost analysis
}

We teachers of benefit-cost analysis (BCA) face a continuing challenge to interest and ideally inspire our students. It is also challenging to keep up with the expanding body of theory and applications. Just preparing for multiple classes and dealing with evaluations seems to fill the available time. This volume, Teaching Benefit-Cost Analysis: Tools of the Trade (TBCA), provides 19 chapters from 24 experienced international authors who make available their teaching, research and practical skills at your disposal. Each contributor was asked to provide a teaching module, here presented as a chapter, to present their favorite topic or to provide key insights into conveying difficult topics. Each chapter is an independent essay; a teacher's digest from which you can select whatever is consistent with your style and interests. Abstracts for each chapter help you hone in on specific topics. And you can always assign chapters as supplemental reading!

But first, who are we teaching and how do we teach it? I asked contributors to provide their syllabi, and with the help of Nate Pritchard, found more on the Internet. Syllabi only provide an insight into the structure of the course, but what I found was:

- Most courses appear to be upper level undergraduate or applied graduate studies such as policy or health care. This book is targeted at that audience, with somewhat less attention to health care and to more advanced students.

- Most BCA teachers appear to provide conceptual and quantitative teachings, often with some case studies. TBCA provides such teachers with a wide array of specific topics in addition to those already mentioned. Teachers looking for material on more conceptual matters or course design might look at Harberger (on Harberger Triangles writ large) in Chapter 2, Robinson on valuing mortality risk reductions (the value per statistical life) (Chapter 8), Catalano and Florio on designing a short course for professionals (Chapter 7) and Shapiro on integrating cases into the classroom in Chapter 18 (with examples). Griffiths and Dockins bring their mixture of government and academic expertise to the issue defining the baseline 
in Chapter 3 along with Mendeloff on the arithmetic of efficiency and the challenges of marginal analysis (Chapter 9). Teachers looking for material on specific skills might consider a class exercise in simulation (Farrow, Chapter 19), or the challenge of finding a market failure from well-meaning students who just want to make something happen (Dudley, Chapter 6).

- Specific and controversial topics are included here as well. Addiction is addressed by Weimer (Chapter 13), distributional issues by Krutilla (Chapter 17), education by Belfield, Bowden and Levin (Chapter 16), land use and transport by Quinet (Chapter 14) and research infrastructure by Florio and Pancotti (Chapter 15).

- There is often a distinction between general BCA and health BCA. This is most obvious in the choice of textbooks. About 80 percent of the syllabi used texts (easily found on the web) such as Boardman, Greenberg, Vining and Weimer (Weimer on addiction writes in Chapter 13, Greenberg on labor writes in Chapter 10); Zerbe and Bellas (Zerbe writes on standing in Chapter 4), and Bellinger writes on decision rules in Chapter 1. However, almost 20 percent of the courses use health-based textbooks such as Drummond, Sculpher, Torrance, O'Brien and Stoddart or Brent. Teachers of those health classes may benefit most from the general skills chapters presented here, or the discussion of health, BCA and alternative utility measures presented by Salkever in Chapter 12.

- There are a few more advanced chapters such as those dealing with partial and general equilibrium (Harberger, Chapter 2; Johansson and Kriström, Chapter 5) and risk and uncertainty (Treich, Chapter 11) that may be most useful for the more advanced courses and students (or we faculty!).

Besides the essential inputs from the contributing authors, the book would not have become a reality without the encouragement of Alan Sturmer at Edward Elgar and the meticulous and timely assistance of Dr Mary Kokoski, an economist of note in her own right. Many of the authors are active with the Society for Benefit-Cost Analysis (SBCA) and publish frequently in its Journal of Benefit-Cost Analysis. Although there is no formal tie between the book and that organization, I think there is a commonality of purpose in improving and applying BCA. Ultimately, teaching is an exchange with students and I appreciate, more in the long run than the short run, the push from students to explain or develop topics more clearly. Additionally, I thank Kelly Hodges, Crystal Proctor, Jacqueline Pennisi and Nate Pritchard of UMBC for their important assistance at various points and the very professional support from multiple hands at 
Edward Elgar throughout the process. Dr Elaine A. King, my spouse, provided encouragement and showed remarkable patience. Finally, there are the teachers who influenced me substantively or pedagogically over the years and to whom I owe a great deal of thanks; among them are Gregory M. Duncan, Maureen Cropper, Lane Rawlins, Francis Ferguson, Walter Butcher, Donald Bushaw and R.K. Goto. Robert (Bob) Hahn brought me back to BCA after many years' absence.

There is a certain humor as I recall telling one of my BCA teachers that I was uneasy with a BCA in the absence of distributional issues being treated in an integrated way. I still don't believe rigidly in the results of a BCA but it is indeed, as a colleague says, "Where the economic rubber meets the road." BCA was one of two themes I brought to my post as Chief Economist of the Government Accountability Office (GAO), although I called it economic performance in that setting, while the second theme was risk - also common in BCA.

It is in teaching the numerous assumptions and the connections between data, theory and results that I renew my appreciation for the intellectual construct of BCA and the power of its purpose. Ultimately, it is your students' hands that will hold the future of many investments, programs, policies and BCA itself; please teach them well.

\section{Scott Farrow}

Professor/UMBC,

Affiliate Faculty/University of Southern California-CREATE Guest Investigator/the Woods Hole Oceanographic Institution 